\title{
KALIBRASI MODEL HARGA OPSI CALL EROPA
}

\author{
Ilham Falani \\ Program Studi Teknik Industri, Universitas Indraprasta PGRI \\ Email : ilham.falani@sci.ui.ac.id
}

\begin{abstract}
Abstrak
Investor perlu memiliki strategi dalam menentukan harga wajar untuk sebuah opsi. Salah satu strategi yang dapat digunakan adalah mempelajari model harga opsi Heston. Pada model harga opsi diperlukan beberapa nilai parameter yang harus ditentukan terlebih dahulu melalui kalibrasi. Kalibrasi dapat dipandang sebagai masalah optimasi nonlinear, yakni dengan meminimumkan nilai suatu fungsi objektif. Algoritma Particle Swarm Optimization merupakan salah satu metode iteratif yang dapat digunakan dalam menentukan solusi masalah optimasi nonlinear. Selanjutnya hasil kalibrasi digunakan untuk menentukan harga wajar opsi. Data yang digunakan dalam makalah ini adalah data 50 harga opsi pasar saham Apple Inc. Berdasarkan hasil implementasi yang dilakukan, algoritma Particle Swarm Optimizationmenunjukan kinerja yang cukup baik.
\end{abstract}

Kata kunci : Particle swarm optimization, kalibrasi, model harga opsi Heston

\section{Pendahuluan}

Opsi adalah salah satu jenis kontrak yang populer diperdagangkan di pasar derivatif. Opsi merupakan kontrak yang berisi hak untuk membeli atau menjual suatu aset dengan harga dan waktu tertentu yang telah menjadi kesepakatan antara penjual dan pembeli opsi.Penentuan harga opsi merupakan hal yang penting untuk diketahui. Investor perlu memiliki strategi dalam menentukan harga opsi.Melalui strategi tersebut investor diharapkan dapat mengetahui harga wajar (fair) opsi. Salah satu strategi untuk menentukan harga opsi adalah menggunakan model harga opsi Heston. Model harga opsi Heston memiliki limaparameterbebasyangdapat ditentukan melalui kalibrasi. Kalibrasi merupakan hal penting yang perlu diperhatikan dalam mempelajari penentuan harga opsi, karena nilai parameter yang diperoleh melalui kalibrasi sangat mempengaruhi keakuratan model. Menurut Kavin Sin (2010), algoritma Particle Swarm Optimization (PSO) merupakan algoritma yang memiliki kinerja yang baik dalam mencari solusi masalah optimasi. Berdasarkan informasi tersebut penulis tertarik untuk meneliti lebih lanjut implementasi algoritma PSO pada kalibrasi model harga opsi Heston.

\section{Tinjauan Pustaka}

Opsi

Menurut Hull (2003), Opsi merupakan sebuah kontrak yang berisi hak bagi pemegang opsi (holder) untuk menjual atau membeli aset sekuritas yang mendasarinya (underlying asset) pada waktu dan harga tertentu. Aset yang mendasari sebuah opsi dapat berupa: Saham, indeks saham, kurs, komoditas, dan lain-lain. Pemegang opsi perlu membayar sejumlah uang atas hak yang diperolehnya kepada penerbit opsi (writter) yang disebut harga opsi. Pada tesis ini aset sekuritas dasar yang digunakan adalah saham, sehingga pembahasan selanjutnya akan difokuskan pada opsi saham.

Berdasarkan transaksinya, opsi dibagi menjadi dua jenis yaitu (Hull, 2003):

1. Opsi Call,kontrak yang memberikan hak kepada pemegang opsi untuk membeli saham pada waktu dan harga tertentu.

2. Opsi Put,kontrak yang memberikan hak kepada pemegang opsi untuk menjual saham pada waktu dan harga tertentu.

Berdasarkan waktu pelaksanaannya, opsi dibagi menjadi dua jenis yaitu (Hull, 2003):

1. Opsi Eropa, opsi yang hanya dapat dilaksanakan pada saat jatuh tempo.

2. Opsi Amerika, opsi yang dapat dilaksanakan kapan saja sampai dengan tanggal jatuh 
tempo.

Pemegang opsi harus membayar sejumlah uang atas hak yang diperolehnya kepada penerbit opsi. Pemegang opsi perlu memiliki strategi dalam menentukan besarnya harga yang wajar untuk opsi. Salah satu strategi yang dapat digunakan oleh pemegang opsi dalam menentukan harga opsi yang wajar adalah dengan menggunakan model harga opsi Heston. Sebelum membahas model harga opsi Heston, terlebih dulu dibahas persamaan diferensial stokastik yang menjadi dasar model pergerakan harga saham.

\section{Persamaan Diferensial Stokastik}

Pada subbab ini dibahas mengenai persamaan diferensial stokastik yang akan diawali dengan pembahasan tentang proses Wiener standar.

Proses Wiener standar pada interval $[0, T]$ didefinisikan sebagai sebuah variabel acak $W(t)$, $t \in[0, T]$ dan memenuhi kondisi berikut ini,

(Higham, 2010)

1. $\quad W(0)=0($ probabilitas 1$)$.

2. Untuk $0 \leq s<t \leq T$, variabel acak yang ditentukan oleh perubahan (increment), $W(t)-W(s)$ berdistribusi normal dengan mean nol dan variansi $t-s$.

3. Untuk $0 \leq s<t<u<v \leq T$, perubahan $W(t)-W(s)$ dan $W(v)-W(u)$ saling bebas.

Proses Wiener juga dikenal sebagai proses gerak Brown (Brownian motion process). Pada tahun 1982, Robert Brown melakukan penelitian terhadap gerakan sejumlah partikel yang tidak beraturan yang dikenal dengan gerak Brown, kemudian hasil penelitian tersebut dipergunakan dalam memodelkan pergerakan harga saham (Ross, 2010).

Model pergerakan harga saham dinyatakan dalam persamaan diferensial stokastik. Pergerakan harga saham merupakan sebuah proses stokastik karena harga saham dapat berubah secara acak pada selang waktu tertentu dengan pola yang tidak terduga.

Definisi Misalkan $\{W(t), t \geq 0\}$ merupakan sebuah proses Wiener dan $\{X(t), t>0\}$ merupakan sebuah proses stokastik, maka persamaan

$d X(t)=\mu(t, X(t)) d t+\sigma(t, X(t)) d W(t)$,

disebut persamaan diferensial stokastik, suku $\mu(t, X(t))$ dan $\sigma(t, X(t))$ berturut-turut merepresentasikan koefisien drift dan diffusion. (Klebaner, 2005)

Untuk mendapatkan solusi dari persamaan diferensial stokastik dibutuhkan formula Ito.

Lema (formula Ito). Misalkan proses stokastik $X_{t}$ dengan persamaan diferensial stokastik

$d X(t)=\mu(t, X(t)) d t+\sigma(t, X(t)) d W(t)$,

dan $f(t, X(t))$ adalah fungsi kontinu yang memiliki turunan $\frac{d f(t, X(t))}{d t}, \frac{d f(t, X(t))}{d X(t)}, \frac{d^{2} f(t, X(t))}{d X(t)^{2}}$ yang kontinu. Maka $f(t, X(t))$ adalah proses diferensial stokastik dengan

$$
\begin{gathered}
d f\left(t, X_{t}\right)=\left(\frac{\partial f(t, X(t))}{\partial t}+\mu \frac{\partial f(t, X(t))}{\partial X_{t}}+\frac{1}{2} \sigma^{2} \frac{\partial^{2} f(t, X(t))}{\partial X_{t}^{2}}\right) d t \\
+\sigma \frac{\partial\left(t, X_{t}\right)}{\partial X(t)} d W(t),
\end{gathered}
$$


Persamaan di atas dikenal dengan formula Ito (pembahasan secara detail dapat dilihat pada Papanicolaou, 2013).

\section{Gauss Lobatto Integration}

Gauss Lobatto integration adalah salah satu metode numerik yang sering digunakan untuk aproksimasi intergral secara adaptive. Bentuk umum Gauss Lobatto integration sebagai berikut (Weisstein, 2013):

$$
I(f) \equiv \int_{-1}^{1} f(x) d x \approx w_{0} f(-1)+\sum_{i=1}^{N-1} w_{i} f\left(x_{i}\right)+w_{N} f(1),
$$

dimana $x_{i}$ untuk $i=1,2, \ldots N-1$ merupakan akar-akar dari polinomial $P_{N-1}^{\prime}(x)$, dengan $P(x)$ adalah polinomial Legendre. $w_{i}$, untuk $i=1,2, \ldots . N$ adalah fungsi bobot untuk $x_{i}$, dengan persamaan sebagai berikut,

$$
\begin{aligned}
& w_{i}=\frac{2 N}{\left(1-x^{2}\right) P^{w}{ }_{N-1}\left(x_{i}\right) P_{m}^{\prime}\left(x_{i}\right)} \\
& =\frac{2}{N(N-1)\left[P_{N-1}\left(x_{i}\right)\right]^{\wedge} 2} .
\end{aligned}
$$

dan titik-titik akhirnya adalah

$w_{1, N}=\frac{2}{N(N-1)^{*}}$

Himpunan polinomial Legendre didefinisikan sebagai sebuah himpunan $\left\{P_{0}(x), P_{1}(x), \ldots, P_{N}(x), \ldots .,\right\}$ dengan sifat-sifat sebagai berikut (Burden dan Faires, 2010)

1. Untuk setiap $N, P_{N}(x)$ adalah polinomial berderajat $N$.

2. $\int_{-1}^{1} P(x) P_{N}(x) d x=0$ dimana $P(x)$ adalah sebuah polinomial berderajat $<N$.

Berikut adalah beberapa polinomial Legendre pertama,

$$
\begin{aligned}
P_{0}(x)=1, \quad P_{1}(x)=x, \quad P_{2}(x)=x^{2}-\frac{1}{3} x \\
P_{3}(x)=x^{3}-\frac{3}{5} x, \operatorname{dan} P_{4}(x)=x^{4}-\frac{6}{7} x^{2}+\frac{3}{35^{*}}
\end{aligned}
$$

Error yang dihasilkan Gauss Lobatto integration adalah,

$E=\frac{n(n-1)^{3} 2^{2 n-1}[(n-2) !]^{4}}{(2 n-1)[(2 n-2) !]^{3}} f^{(2 n-2)}(\xi)$, dengan $\xi \in(-1,1)$.

Pada perangkat lunak MATLAB terdapat fungsi quad 1(fun,a,b) yang mengimplementasikan Gauss Lobatto integrationuntuk integral suatu fungsi pada selang $[a, b]$.

\section{Model Harga Opsi Heston}

Pada tahun 1993, Heston mengusulkan sebuah model volatilitas stokastik saham, yaitu

$$
\begin{array}{r}
d S_{t}=\mu S_{t} d t+S_{t \sqrt{v_{t}}} d Z_{1}, \\
d v_{t}=\kappa\left(\theta-v_{t}\right) d t+\eta \sqrt{v_{t}} d Z_{2},
\end{array}
$$

dimana $S_{t}$ menyatakan harga saham pada waktu ke $t$ dan $\left(\sqrt{v_{t}}\right)$ dengan $t \geq 0$ menyatakan proses volatilitas harga saham dengan $v_{t}$ yang memenuhi persamaan (2). $\mu$ menyatakan ekspektasi tingkat imbal hasil saham. $\kappa, \theta, \eta$ merupakan parameter-parameter bernilai positif yang secara berturut-turut menyatakan laju dari pengembalian rata-rata $v_{t}$, tingkat 
rata-rata jangka panjang dari $v_{t}$, dan volatilitas dari $v_{t}$. Dua buah gerak Brown $Z_{1}$ dan $Z_{2}$ yang saling berkorelasi, dimana $\rho$ adalah korelasi antara aset $S_{t}$ dan volatilitas $v_{t}$.

Berdasarkan model volatilitas stokastik tersebut Heston mengemukakanClosed Form Solutionsebagai berikut (Poon, 2011):

$$
\begin{aligned}
& C(S, v, t)=e^{x} P_{1}-e^{(r t-r T)} K P_{2}, \\
& \text { dengan } x=\ln S . \\
& \text { Untuk } j=1,2 \text { dimana } u_{1}=\frac{1}{2}, u_{2}=-\frac{1}{2}, a=\kappa \theta, b_{1}=\kappa+\lambda-\eta \rho, b_{2}=\kappa+\lambda . \\
& d_{j}=\sqrt{\left(\rho \eta i \phi-b_{j}\right)^{2}-\eta^{2}\left(2 u_{j} i \phi-\phi^{2}\right),} \\
& g_{j}=\frac{b_{j}-\rho \eta i \phi+d_{j}}{b_{j}-\rho \eta i \phi-d_{j}}, \\
& D_{j}(\tau ; \phi)=\frac{b_{j}-\rho \eta i \phi+d_{j}}{\eta^{2}}\left[\frac{1-e^{d_{j} \tau}}{1-g_{j} e^{d_{j} \tau}}\right], \\
& E_{j}(\tau ; \phi)=r i \phi \tau+\frac{a}{\eta^{2}}\left[\left(b_{j}-\rho \eta i \phi+d\right) \tau-2 \ln \left(\frac{1-g_{j} e^{d_{j} \tau}}{1-g_{j}}\right)\right], \\
& f_{j}=e^{E_{j}+D_{j} v+i \phi x}, \\
& P_{j}=\frac{1}{2}+\frac{1}{\pi} \int_{0}^{\infty} \operatorname{Re}\left[\frac{e^{i \phi x} f_{j}(\phi)}{i \phi}\right] d \phi,
\end{aligned}
$$

$C(S, v, t)$ merupakan harga opsi call saham $S_{t} . K, T$ berturut-turut adalah strike price dan maturity date yang disepakati antara penjual dan pembeli opsi. $r$ adalah tingkat suku bunga bebas resiko.

\section{Metodologi Penelitian}

Metode penelitian yang digunakan dalam penelitian adalah studi pustaka untuk lebih memahami tentang kalibrasi model harga opsi call Eropa Heston, serta mempelajari algoritma PSO sebagai teknik dalam melakukan kalibrasi. Dilanjutkan dengan penyusunan algoritma PSO dan mengimplementasikannya dalam kalibrasi model harga opsi call Eropa Heston. Implementasi ini dilakukan dengan menggunakan bantuan perangkat lunak Matlab R2013.

\section{Masalah Optimasi pada Kalibrasi Model Harga Opsi Heston}

Untuk menentukan harga opsi call Eropa dengan model harga opsi Heston, diperlukan nilai parameter $\kappa, \theta, \eta, \rho, v_{0}$. Nilai parameter model harga opsi Heston tidak dapat diperoleh secara langsung dari harga pasar opsi yang diamati, tetapi melalui kalibrasi. Kalibrasi dipandang sebagai masalah optimasi kuadrat terkecil nonlinear, dengan meminimumkan fungsi objektif sebagai berikut(Seungg, Hyejin, dan Lee, 2010)

$$
\min \sum_{i=1}^{N}\left|C_{i}^{\text {model }}-C_{i}^{\text {market }}\right|^{2},
$$

dengan $N$ adalah banyaknya data harga opsi pasar yang digunakan, $C_{i}^{\text {model }}$ adalah harga opsi ke $i$ berdasarkan model harga opsi Heston. $C_{i}^{\text {market }}$ adalah harga opsi ke $i$ berdasarkan harga opsi pasar. Harga opsi pasar yang digunakan dalam penelitian ini adalah data harga opsi saham Apple Inc (AAPL) yang diunduh pada tanggal 20 April 2014 dan diakses melalui www.nasdaq.com. Data yang digunakan terdiri dari 50 harga opsi saham dengan harga saham awal $S_{0}=\$ 112.21$, tingkat bunga bebas resiko 
$r=0.02$, harga kesepakatan $K$ dan waktu pelaksanaan $T$ yang berbeda-beda untuk setiap harga opsi pasar.

Pada masalah optimasi ini terdapat fungsi-fungsi kendala yang harus dipenuhi untuk menjamin proses variansi pada persamaan $d v_{t}$ bernilai positif. Kendala tersebut adalah (Mikhailov dan Nogel, 2012)

1. $\kappa>0,2 . \sigma>0,3 . \eta>0, \quad 4 .-1<\rho<1,5 . v_{0}>0,6.2 \kappa \sigma-\eta^{2}>0$.

Pencarian solusi masalah optimasi pada kalibrasi model harga opsi Heston ini dilakukan dengan algoritma PSO.

\section{Algoritma PSO pada Kalibrasi Model Harga Opsi Heston}

Algoritma Particel Swarm Optimization merupakan salah satu teknik numerik untuk menyelesaikan masalah optimasi fungsi nonlinear. Teknik ini dikemukakan oleh Eberhart dan Kennedy pada tahun 1995. Konsep dasar algoritma PSO diinspirasi dari perilaku sosial hewan, contohnya perilaku burung terbang secara berkelompok (Brownlee, 2011).

Pada algoritma PSO tiap objek burung dipandang sebagai sebuah partikel. Sebuah partikel dalam ruang memiliki posisi yang dinyatakan sebagai vektor koordinat yang disebut vektor posisi. Vektor posisi ini dianggap sebagai keadaan yang sedang ditempati oleh partikel di ruang pencarian. Setiap posisi dalam ruang pencarian merupakan solusi potensial yang dapat dievaluasi menggunakan fungsi objektif. Setiap partikel bergerak dengan kecepatan tertentu. Konsep tersebut disimulasikan dalam ruang dimensi tertentu menggunakan sejumlah iterasi dan pada setiap iterasi posisi partikel akan semakin mengarah ke target yang dituju. Simulasi ini dilakukan hingga maksimum iterasi dicapai atau dapat juga digunakan kriteria penghentian iterasi yang lain (Eberhart dan Kennedy, 1995). Beberapa notasi dan istilah dalam PSO yang digunakan adalah (Englebrecth, 2007):

- Kelompok (Swarm) adalah kumpulan dari objek (partikel)

- Particle $P_{i}^{(k)}$ adalahsolusi potensial ke $i$ dalam kelompok pada iterasi ke $k . P_{i}^{(k)}$ dalam kelompok dinyatakan sebagai vektor posisi berdimensi $j$ yang dapat ditulis sebagai $P_{i}^{(k)}=\left[x_{i 1}^{(k)}, x_{i 2}^{(k)}, \ldots, x_{i j}^{(k)}\right]$,

- Ukuran kelompok $N_{p}$ merepresentasikan banyaknya partikel yang ada dalam kelompok.

- Jumlah iterasi $N_{G}$ merepresentasikan jumlah maksimal iterasi yang dilakukan, $k=0,1,2, \ldots N_{G}$ dengan $N_{G} \in \mathbb{N}$.

- $P_{b e s t i \bar{i}}^{(k)}\left(\right.$ Particlebest) adalah posisi terbaik $P_{i}^{(k)}$ berdasarkan nilai evaluasi fungsi objektif terbaik $P_{i}^{(k)}{ }_{j}^{(k)} F\left(P_{b e s t_{i}^{*}}^{(k)}\right)$.

- $F_{b \in s t_{i}}$ adalah nilai evaluasi fungsi objektif terkecil dari $P_{i}^{(k)}$.

- $P_{\text {best } t_{\text {gbest }}}\left(\right.$ Global Best) adalah posisi terbaik diantara seluruh $P_{i}^{(k)}$ dalam kelompok, dan $P_{\text {best }_{\text {gbest }}}=\left[x_{\text {bestgbest } 1_{\text {best }}{ }_{\text {gbestz }}} \ldots x_{\text {best }_{\text {gbest }} j}\right]$.

- Gbest adalah nilai evaluasi fungsi objektif terkecil dari diantara seluruh $P_{i}^{(k)}$.

- Komponen kecepatan (inertia) $V_{i}^{(k)}$ adalah kecepatan dari $P_{i}^{(k)}$, yang dapat ditulis sebagai $V_{i}^{(k)}=\left[v_{i 1}^{(k)}, v_{i 2}^{(k)}, \ldots v_{i j}^{(k)}\right]$,

- Bobot Inertia $\delta^{(k)}$ adalah fungsi bobot untuk kecepatan partikel sebelumnya, $V_{i}^{(k-1)}$,

- Koefisien akselerasi $c_{1}$ dan $c_{2}$ berturut-turut merupakan koefisien bobot untuk komponen kognitif dan komponen sosial, Nilai $c_{1}$ dan $c_{2}$ yang digunakan $c_{1}=c_{2}=2$ (Talukder, 2010). 
Kecepatan dari tiap partikel akan terus diperbaharui selama proses optimasi dengan menggunakan persamaan di bawah ini (Eberhart dan Kenedy, 1995),

$$
V_{i}^{(k)}=\delta^{(k)} V_{i}^{(k-1)}+[\underbrace{c_{1} r_{1}\left(P_{\text {best }_{i}}^{(k)}-P_{i}^{(k-1)}\right)}_{\text {Komponen kognitif }}+c_{2} r_{2}(\underbrace{\left.P_{\text {best gbest }}-P_{i}^{(k-1)}\right)}_{\text {Komponen sosial }}] .
$$

Menurut Englebrecth (2007), bobot inertia $\delta^{(k)}$ yang berubah secara dinamis lebih sering digunakan pada masalah optimasi. Pengurangan bobot inertia secara linear pada setiap iterasi berdasarkan persamaan berikut:

$\delta^{(k)}=\delta_{\max }-\left(\frac{\delta_{\max }-\delta_{\min }}{N_{G}}\right)(k-1)$,

dengan $\delta_{\max }$ dan $\delta_{\min }$ berturut-turut adalah nilai awal dan akhir bobot inertiaNilai yang banyak digunakan dalam berbagai penelitian adalah $\delta_{\max }=0.9$ dan $\delta_{\min }=0.4$ (Talukder, 2011).

Pada algoritma PSO, nilai-nilai parameter $k, \theta, \eta, \rho, v_{0}$ dinyatakan sebagai vektor posisi berdimensi lima dari sebuah partikel,

$P_{i}^{(k)}=\left[\kappa_{i}, \theta_{i}, \eta_{i}, \rho_{i}, v_{0_{i}}\right]=\left[x_{i 1}^{(k)}, x_{i 2}^{(k)}, x_{i 3}^{(k)}, x_{i 4}^{(k)}, x_{i 5}^{(k)}\right]$,

dengan partikel $P_{i}^{(k)}$ dengan $i=1,2, \ldots N_{p}$, merupakan solusi potensial ke $i$ dalam kelompok pada iterasi ke $k$. Dalam satu kelompok terdapat sebanyak $N_{p}$ partikel yang akan digunakan dalam ruang pencarian,

$$
P^{(k)}=\left[\begin{array}{llllll}
P_{1}^{(k)} P_{2}^{(k)} & \ldots P_{N_{P}}^{(k)}
\end{array}\right]^{T}=\left[\begin{array}{cccc}
x_{11}^{(k)} & x_{21}^{(k)} & \ldots & x_{N_{P} 1}^{(k)} \\
x_{12}^{(k)} & x_{22}^{(k)} & \ldots & x_{N_{P} 2}^{(k)} \\
x_{13}^{(k)} & x_{23}^{(k)} & \ldots & x_{N P 3}^{(k)} \\
x_{14}^{(k)} & x_{24}^{(k)} & \ldots & x_{N p 4}^{(k)} \\
x_{15}^{(k)} & x_{25}^{(k)} & \ldots & x_{N P 5}^{(k)}
\end{array}\right]^{T} .
$$

Setiap partikel akan terus menerus bergerak mencari solusi masalah optimasi kuadrat terkecil nonlinear hingga kriteria penghentian algoritma dicapai. Kriteria penghentian yang digunakan dalam makalah ini adalah jika jumlah maksimum iterasi telah dicapai. Hasil akhir dari algoritma PSO adalah:

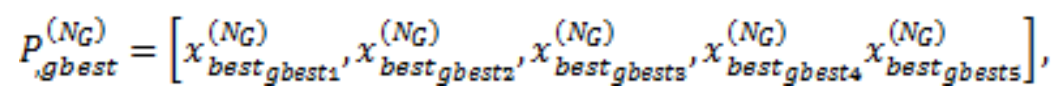

yang merupakan global best, yakni posisi terbaik diantara seluruh partikel yang menghasilkan nilai evaluasi fungsi objektif yang paling optimal untuk masalah optimasi pada kalibrasi model harga opsi Heston. Kelima elemen dalam vektor posisi tersebut merepresentasikan nilai parameter optimal model berdasarkan satu kali simulasi implementasi algoritma PSO.Satu simulasi didefinisikan sebagai satu kali implementasi algoritma PSO pada kalibrasi model harga opsi Heston hingga dihasilkan nilai parameter model Heston $\left(\kappa, \theta, \eta, \rho, v_{0}\right)$.

Penghitungan nilai eror simulasi menggunakan metode mean squared error

$$
\epsilon=\sum_{i=1}^{n} \frac{\left(c_{i}^{\text {market }}-c_{i}^{\text {model }}\right)^{2}}{n} .
$$


Berikut adalah langkah-langkah implementasi algoritma PSO pada Kalibrasi model Heston (Seungho, Hyejin, dan Lee, 2010):

1. Tentukan parameter $N_{p}, N_{G}, c_{1}, c_{2}, \delta_{\max }$ dan $\delta_{\min }$ yang digunakan.

2. Inisialisasi posisi $P_{i}^{(0)}$ dan kecepatan $V_{i}^{(0)}$ partikel awal secara acak.

3. Evaluasi nilai fungsi objektif $\left(F_{i}\right)$ untuk setiap partikel

4. Tentukan Pbest $_{i}$ berdasarkan nilai evaluasi fungsi objektif $F_{i}$. Jika $F_{i}<F_{b \in s t_{i}}$, maka $P_{\text {best }}$ adalah posisi sekarang $P_{i}^{(k)}$.

5. Tentukan Gbest. Jika $F_{i}<$ Gbest, maka $F_{i}$ tersebut merupakan Gbest gbest $_{\text {. }}$.

6. Perbaharui $V_{i}^{(k)}$

7. Perbaharui $P_{i}^{(k)}=P_{i}^{(k-1)}+V_{i}^{(k)}$, selanjutnya lakukan loop kembali menuju langkah nomor 3. Loop berakhir jikaN $N_{G}$ dicapai dan diperoleh $P_{a b \text { bast }}^{\left(N_{G}\right)}$

8. Analisis kinerja algoritma PSO untuk satu simulasi

\section{Implementasi Algoritma Particle Swarm Optimization pada Kalibrasi}

Alur kerja kalibrasi model harga opsi Heston dengan menggunakan algoritma PSO telah dijelaskan seperti pada gambar di bawah ini,

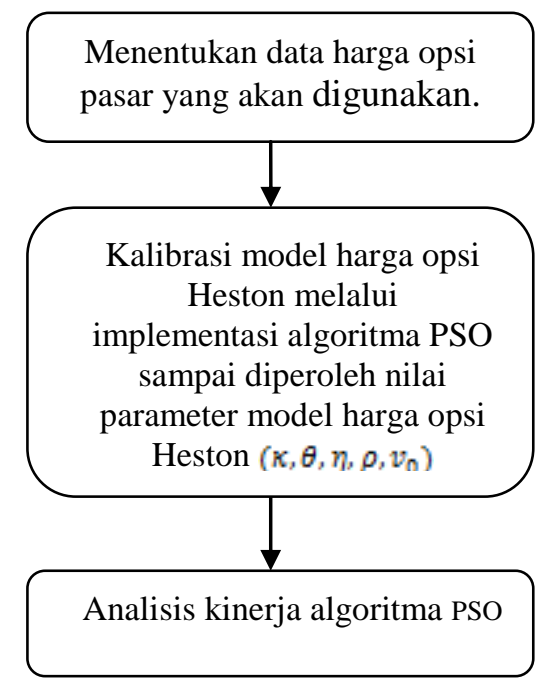

Gambar 2. Alur Kerja Kalibrasi Model Harga Opsi Heston dengan Algoritma PSO

\section{Model Harga Opsi Heston}

Implementasi algoritma PSO pada kalibrasi model harga opsi Heston dalam makalah ini menggunakan nilai $N_{p}$ dan $N_{G}$ yang berbeda-beda, seperti pada tabel di berikut:

\section{Tabel 1. Kombinasi $N_{P}$ dan $N_{G}$}

\begin{tabular}{crr}
\hline No & \multicolumn{1}{c}{$\boldsymbol{N}_{\boldsymbol{P}}$} & $\boldsymbol{N}_{\boldsymbol{G}}$ \\
\hline 1 & 20 & 50 \\
2 & 20 & 100 \\
3 & 20 & 200 \\
4 & 40 & 50 \\
5 & 40 & 100 \\
6 & 40 & 200 \\
7 & 60 & 50 \\
8 & 60 & 100 \\
\hline
\end{tabular}




\begin{tabular}{lll}
\hline 9 & 60 & 200 \\
\hline
\end{tabular}

Berdasarkan kombinasi nilai $N_{P}$ dan $N_{G}$ pada Tabel 1, simulasi dilakukan sejumlah 500 untuk setiap kombinasi sesuai pada skema di bawah ini:

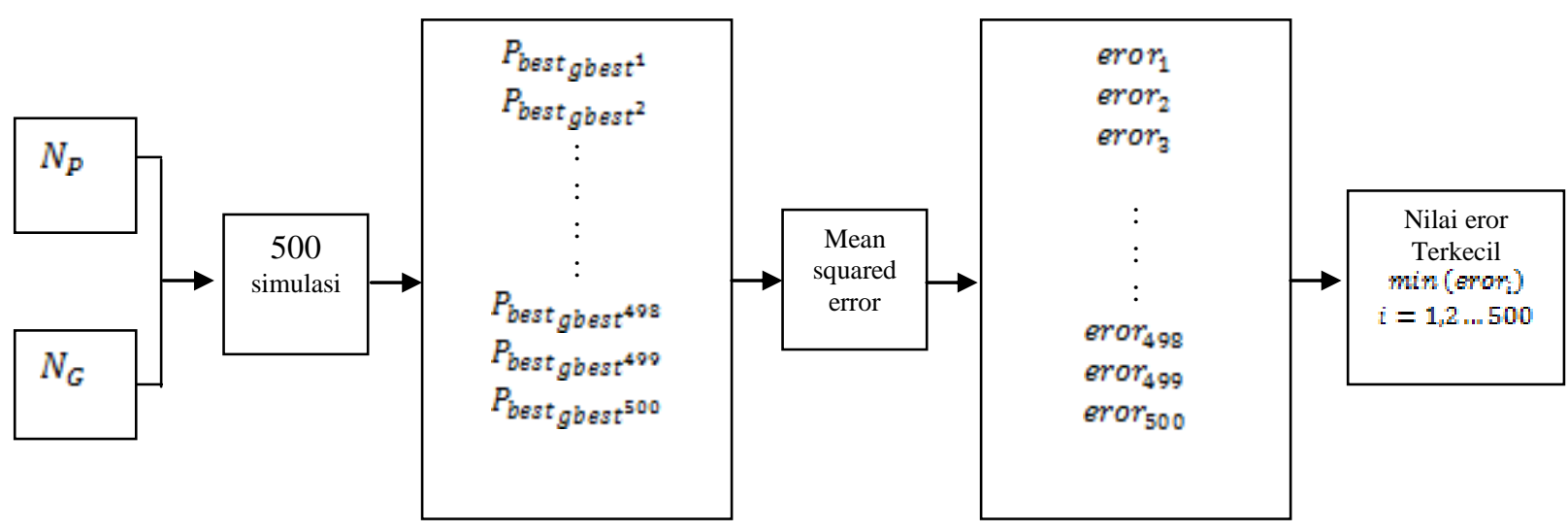

Gambar 1. Alur Simulasi untuk Tiap Kombinasi $N_{P}$ dan $N_{G}$

Dari 500 simulasi yang dilakukan, dihasilkan 500 posisi partikel terbaik untuk masingmasing simulasi berupa $P_{\text {best }}$ gbast $^{i}$ dengan $i=1,2, \ldots, 500$ yang berisi kelima nilai parameter $\left(\kappa, \theta, \eta, \rho, v_{0}\right)$. Selanjutnya kinerja algoritma PSO pada setiap simulasidianalisis menggunakan metodemean squared eror dengan mensubtitusikan kelima nilai parameter yang diperoleh sehingga dihasilkan $C^{\text {model }}$, sedangkan $C^{\text {market }}$ adalah 50 data harga pasar opsi saham yang digunakan. Selanjutnya dihitung jumlah kuadrat selisih antara $C^{\text {model }}$ dan $C^{\text {market }}$, kemudian dibagi dengan banyaknya data yang digunakan. Sehingga diperoleh 500 nilai eror berdasarkan 500 simulasi. Untuk mengetahui nilai eror terkecil yang dihasilkan oleh 500 simulasi dapat ditentukan denganmenghitung $\min \left(\min \left(\operatorname{eror}_{i}\right)\right), i=1,2, \ldots, 500$. Nilai minimum dari minimum eror merepresentasikan kinerja algoritma paling optimal yang dapat diperoleh kombinasi nilai $N_{P}$ dan $N_{G}$ pada Tabel 1 .

\section{Hasil dan Pembahasan}

Hasil simulasi sembilan kombinasi nilai $N_{P}$ dan $N_{G}$ pada Tabel 1adalah sebagai berikut,

Tabel 2. Hasil Implementasi Algoritma PSO 


\begin{tabular}{|c|c|c|c|c|c|c|c|c|c|c|}
\hline \multirow[t]{2}{*}{ No } & \multirow[t]{2}{*}{$N_{P}$} & \multirow[t]{2}{*}{$N_{G}$} & \multirow[b]{2}{*}{ Simulasi } & \multicolumn{5}{|c|}{ Particle best } & \multirow{2}{*}{$\begin{array}{c}\text { Cost } \\
\text { value }\end{array}$} & \multirow{2}{*}{$\begin{array}{c}\text { Minimum } \\
\text { eror }\end{array}$} \\
\hline & & & & $\boldsymbol{K}$ & $\theta$ & $\eta$ & $\rho$ & $v_{0}$ & & \\
\hline 1 & 20 & 50 & 500 & 49.266 & 0.0786 & 2.7784 & -0.2012 & 0.0929 & $5.2757 \mathrm{e}+00$ & 0.1055 \\
\hline 2 & 20 & 100 & 500 & 9.2711 & 0.0754 & 0.2526 & -0.7930 & 0.0828 & $5.1435 \mathrm{e}+00$ & 0.1029 \\
\hline 3 & 20 & 200 & 500 & 47.947 & 0.0766 & 1.2099 & -0.4436 & 0.0836 & $4.9795 \mathrm{e}+00$ & 0.0996 \\
\hline 4 & 40 & 50 & 500 & 31.809 & 0.0766 & 0.9861 & -0.3338 & 0.0861 & $5.1764 \mathrm{e}+00$ & 0.1035 \\
\hline 5 & 40 & 100 & 500 & 9.0427 & 0.0755 & 0.2098 & -0.8906 & 0.0827 & $5.1483 e+00$ & 0.1030 \\
\hline 6 & 40 & 200 & 500 & 48.111 & 0.0805 & 1.3860 & -0.6122 & 0.0692 & $4.5421 \mathrm{e}+00$ & 0.0908 \\
\hline 7 & 60 & 50 & 500 & 49.631 & 0.0770 & 0.6517 & -0.7922 & 0.0711 & $5.1574 \mathrm{e}+00$ & 0.1030 \\
\hline 8 & 60 & 100 & 500 & 46.016 & 0.0791 & 1.8994 & -0.5033 & 0.0936 & $4.7682 e+00$ & 0.0954 \\
\hline 9 & 60 & 200 & 500 & 48.672 & 0.0961 & 2.9952 & -0.3909 & 0.0413 & $3.8355 \mathrm{e}+00$ & 0.0767 \\
\hline
\end{tabular}

Pada kolom ke 11 Tabel 2 dapat dilihat nilai minimum eror dari 500 simulasi yang dilakukan untuk setiap kombinasi $N_{P}$ dan $N_{G}$. Nilai terkecil dari minimum eror adalah 0.0767. Hal ini berarti berdasarkan 500 simulasi yang dilakukan implementasi algoritma PSO menggunakan kombinasi $N_{P}=60$ dan $N_{G}=200$ menghasilkan kinerja yang lebih baik dibandingkan dengan hasil implementasi kombinasi yang lain. Dengan demikian Particle bestdengan $\kappa=48.672, \theta=0.0961, \eta=2.9952, \rho=-0.3909$, dan $v_{0}=0.0413$ pada baris kesembilan kolom kelima sampai dengan sembilan yang menghasilkan cost valueterkecil merepresentaikan kelima nilai parameter yang paling optimal berdasarkan simulasi yang telah dilakukan. Selanjutnya nilai parameter tersebut dapat digunakan dalam model harga opsi Heston untuk memprediksi harga opsi pasar yang diamati. Nilai minimum eror merepresentasikan prediksi rata-rata selisih harga opsi yang dihasilkan oleh model harga opsi Heston dan harga opsi pasar adalah sebesar \$0.0767. Hal ini menunjukan bahwa implementasi algoritma PSO pada kalibrasi model harga opsi Heston menunjukan kinerja yang cukup baik.

\section{Simpulan dan Saran}

Kalibrasi model harga opsi Heston terdiri dari beberapa tahapan yakni : Menentukan data harga opsi pasar yang digunakan, kalibrasi model harga opsi Heston dengan menggunakan algoritma PSO untuk mencari solusi minimum dari masalah optimasi kuadrat terkecil nonlinear hingga diperoleh nilai-nilai parameter model harga opsi Heston, dan analisis kinerja algoritma PSO dengan menggunakan metode least squared errorsehingga diperoleh nilai eror yang merepresentasikan kinerja algoritma PSO. Berdasarkan hasil implementasi yang telah dilakukan, algoritma PSO menunjukan kinerja yang cukup baik dalam mengaproksimasi nilai parameter model harga opsi Heston. Perlu dilakukan penelitian tentang kalibrasi dengan menggunakan algoritma yang lain untuk dapat terus meningkatkan performa model Heston dalam menentukan harga opsi.

\section{Daftar Pustaka}

Brownlee, J. (2011). Clever Algorithms: Nature-Inspired Programming Recipes. Melbourn: Creative common.

Eberhart, R., \& Kennedy, J. (1995). Particle Swarm Optimization.

Proceedings IEEE International Conference on Neural Networks, Perth, Australia. 1995, pp. 1942-1948.

Engelbrecht, A.P. (2007). Computational Intelligence: An Introduction (2nd. Ed). England: John Wiley and Sons Ltd.

Heston, S.L. (1993). A Closed-Form Solution for Option with Stochastic Volatility with Applications to Bond and Currency Options. Review of Financial Study, vol. 6, pp. 337-343. 
Kao, Chih-Cheng. (2009). Application of Partticle Swarm Optimization in Mechanical Design. Taiwan: Kao Yuan University.

Mikhailov, S. dan Nogel, U. Heston's Stochastic Volatiliy Model Implementation, Calibration and Some Extension. Fraunhofer Institute for Industrial Mathematic, Germany. WILMOTT Magazine.

Poon, S.H. (2011). The Heston Option Pricing. America : Michigan University.

Seungho, Y., Park, H., dan Lee, J. (2010). Robust Calibration of the Stochastic Volatility Model. Journal of Mathematical Finance, 1, 50-57.

Sin, K.(2010). Theses: Numerical Methods for Derivative Pricing with Applications to Barrier Options. Canada: University of Waterloo.

Talukder, S. (2010). Theses: Mathematical modelling and Applications of Particle Swarm Optimization. Sweden : Blekinge Institute of Technology. 